\title{
Inflation Targeting - the Holy Grail of Monetary Policy
}

\author{
Hans Genberg \\ Graduate Institute of International Studies, Geneva
}

\begin{abstract}
Inflation targeting is a statement about the objective of central bank policy and not about operating procedures. Its success depends not only on the actions of the central bank, but requires a broad consensus concerning the proper role of monetary policy in the economy. It also requires the backing of a sound fiscal policy. As countries differ both in economic structure and monetary transmission mechanism, the implementation of inflation targeting must be country specific. Instability over time in the transmission mechanism also implies that inflation targeting strategies must evolve over time to avoid the fate of previous monetary policy targeting practices.
\end{abstract}

(C) The Authors.

All rights reserved. No part of this paper may be reproduced without the permission of the authors. 


\title{
Inflation Targeting - the Holy Grail of Monetary Policy?
}

\author{
Hans Genberg \\ Graduate Institute of International Studies \\ Geneva, Switzerland
}

\begin{abstract}
Inflation targeting is a statement about the objective of central bank policy and not about operating procedures. Its success depends not only on the actions of the central bank, but requires a broad consensus concerning the proper role of monetary policy in the economy. It also requires the backing of a sound fiscal policy. As countries differ both in economic structure and monetary transmission mechanism, the implementation of inflation targeting must be country specific. Instability over time in the transmission mechanism also implies that inflation targeting strategies must evolve over time to avoid the fate of previous monetary policy targeting practices.
\end{abstract}

Revised

August 16, 2002

\section{genberg@hei.unige.ch}

Comments by Michael Salemi on a previous draft are gratefully acknowledged. The paper was revised while the author was a Research Fellow at the Hong Kong Institute for Monetary Research. The excellent work environment of the Institute is gratefully acknowledged. 


\section{Introduction.}

Inflation targeting is being adopted by an increasing number of Central Banks. Almost every day another country is added to the list that contained only a handful off countries only a few years ago. This enthusiasm for inflation targeting naturally leads to the question whether this strategy is merely the latest fashion among central bankers or whether we have finally found the holy grail of monetary policy. The large-scale adoption of the new strategy also begs the question whether it is appropriate for all countries regardless of their economic structure and degree of economic and institutional development.

Seeking to shed some light on these issues, this paper first discusses the essential elements of inflation targeting. In section 2, I argue that inflation targeting is first and foremost a statement about the objectives of monetary policy, and that it should not be about operating procedures. I claim that it is useful to stick to such a narrow definition and not to extend it to include the means and tactics the central bank are using to achieve its goals.

Section 3 argues that inflation targeting should not be based only on a decision of the central bank. In order to be successful it must be founded on a broad popular consensus about the goals of monetary policy, and it must be supported by appropriate policies in other areas, notably fiscal policy.

In section 4, I show that inflation targeting can be compatible with many different operating procedures. Which one is most appropriate in a given context depends critically on the transmission mechanism of monetary policy and on the sources of shocks in the economy. It follows that implementation of an inflation-targeting strategy could look very different from one country to another. What would be an appropriate policy rule in an industrialized country would not necessarily be suitable in an emerging market even if the ultimate goal of the central bank were the same.

Economies evolve over time potentially altering the relationship between policy instruments and outcomes. The celebrated Goodhart's law explained the debacle of monetary targeting by referring to financial innovations weakening the link between money growth and inflation. Section 5 of the paper looks at inflation targeting in this light, and argues that implementation of this strategy has to be flexible enough to incorporate changes in the link between interest rates and inflation that are sure to emerge in the future. Failing such flexibility, inflation targeting will also fall victim to Goodhart's law. 
The paper ends by addressing the question implicit in the title, namely whether inflation targeting is likely to be the last word on monetary policy and whether it is here to stay.

\section{Defining Inflation Targeting.}

Inflation targeting is different from monetary targeting or exchange rate targeting for several reasons. First, the inflation rate can only be influenced with a substantial and perhaps variable lag. In contrast, the money supply and the exchange rate can be quickly influenced by policy. Secondly, the money supply is not in any way an ultimate objective of central bank policy, but the inflation rate can perhaps be thought of as such.

What then is inflation targeting? Mishkin, one of the authors of a recent influential book on the subject ${ }^{1}$, sets out the following five criteria: "(i) the public announcement of medium-term numerical targets for inflation; (ii) an institutional commitment to price stability as the primary goal of monetary policy, to which other goals are subordinated; (iii) an information-inclusive strategy in which many variables, and not just monetary aggregates or the exchange rate, are used for deciding the setting of policy instruments; (iv) increased transparency of the monetary-policy strategy through communication with the public and the markets about the plans, objectives, and decisions of the monetary authorities; and (v) increased accountability of the central bank for attaining its inflation objectives."

While all of these criteria are desirable, some of them are more important than others. How the criteria are interpreted and applied should be country-specific. I will therefore attempt to identify those ingredients are the most essential for a successful monetary policy strategy and those can be considered as icing on the cake.

This raises the question as to what constitutes 'a successful monetary strategy'? I shall take it to mean that monetary policy which contributes most effectively to the economic growth and development of the country. Admittedly this is a very vague criterion, but it almost has to be so in order to avoid a definition of successful that virtually by definition implies a particular strategy.

Inflation targeting is a statement of the objectives of monetary policy. A central bank is following a strategy of strict inflation targeting when it has no other objective than assuring price

\footnotetext{
${ }^{1}$ Bernanke, et. al. (1999).

${ }^{2}$ Mishkin (2000), p. 105.
} 
stability. How price stability is actually defined is a matter that will not be discussed in detail here. Inflation targeting can be compatible with many different definitions, and what is the most appropriate for one country is not necessarily the best for another. The literature contains a discussion of the relative merits of targeting the rate of inflation versus targeting the price level. The essential differences between them is that a central bank that targets the rate of inflation will treat bygones as bygones in the sense that the missing the target one year will not lead the central bank to compensate in the next. Targeting the price level, on the other hand, requires the central bank to achieve a pre-determined path for the price level. This means that an inflation rate above target this year will have to be followed by inflation rates below target for some periods in the future. In this paper I will refer to inflation targeting and achieving price stability interchangeably.

Flexible inflation targeting is a strategy that permits other goals provided that they are subordinated to achieving the inflation target. This raises the question what it means in practice to subordinate other goals to the inflation target. The UK procedure offers one possibility. According to the remit from the Chancellor of the Exchequer, the objective of the Bank of England is to maintain price stability, and subject to that, to support the economic policy of the Government, including its objectives for growth and employment. If the actual inflation rate deviates by 1 percentage point from the target, the Governor of the Bank of England must write a letter to the Chancellor explaining the reason for this deviation, the policy action that will be taken to deal with it, the period within which inflation is expected to return to the target, and how this action meets the Government's monetary policy objectives.

Inflation targeting is a reasonable policy strategy for two reasons:

- Monetary policy can actually achieve a low and stable inflation rate, at least if it is defined as an average over some relatively long (one to two years) time period. It cannot achieve some alternative goals that have been proposed, such as particular values for the rate of unemployment, the level or rate of growth of real income, the real rate of interest, or the real exchange rate.

- Price stability contributes to general economic welfare by rendering the price system more transparent, by reducing certain types of uncertainty that may harm long-term investment, and by eliminating unintended redistribution of income. 
I contend that limiting the definition of inflation targeting to a statement of the objective of monetary policy has several advantages: it would focus the attention on the most important reason why inflation targeting will be beneficial to countries that adopt it; it would recognize that inflation targeting can be compatible with different operating procedures of monetary policy; and it would allow inflation targeting to be adopted in countries in which the institutional infrastructure and other elements do not make it practical to adhere to more wide-ranging definitions of inflation targeting that that have been proposed. I will discuss each of these in turn.

\section{Most cases of excessive inflation have been the consequence of giving the Central Bank inappropriate goals.}

Belief in permanent exploitable trade-off between inflation and unemployment is a major reasons why inflation on occasion got out of hand in many countries in the post WWII period. The thought that the Central Bank could chose a point on a downward sloping Phillips curve fueled political pressure to lower unemployment even if it meant accepting somewhat higher rates of inflation, the cost of which was not regarded as significant at the margin. As unemployment rates were pushed below natural levels, however, inflation ratcheted upward. Attempts to bring inflation under control resulted in cycles of stop-go policies with no sustained gains in employment, but higher-than-desired inflation rates.

A second of inflation bias can be found in the interaction between monetary and fiscal policies. When the central bank attempts to keep interest rates from increasing in the face of substantial government borrowing requirements, the resulting monetization of government debt will fuel inflationary increases in money growth.

Attempts to achieve improvements in competitiveness through currency depreciations is yet another example of the inflationary consequences of inappropriate policy objectives. While such depreciations can achieve their objectives in the short run, they will almost invariably bring about inflation in the medium- to long term due to higher import prices and the resulting increased wage demands.

The lesson to be retained from these examples is that if monetary policy were focused primarily on price stability, then the likelihood of inflation becoming excessive would be substantially reduced, if not eliminated altogether. Of course, as the examples also suggest, it is essential that other government policies, such as budgetary and exchange rate policies, are consistent with the pursuit of price stability. Failing this, conflicts are likely to emerge that 
eventually erode the capacity of the central bank to carry out its mandate. In this context it has been argued that giving the central bank substantial independence will make monetary policy immune to pressures resulting from conflicting goals of economic policy. While such independence is certainly helpful, I will argue below that it is neither a sufficient nor a necessary condition for successful inflation targeting.

Depending on the institutional and economic context, price stability may be achieved with different operating procedures.

If inflation targeting refers not only to the objectives of monetary policy but also to the means these objectives are achieved, then some curious classifications emerge. For example, perhaps the most consistently anti-inflationary Central Banks in the early post Bretton Woods area, the German Bundesbank and the Swiss National Bank could not be portrayed as inflation targeters according to such a definition. For many years both the Bundesbank and the Swiss National Bank set operational targets for the growth of a monetary aggregate. ${ }^{3}$ They also stressed the use of monetary aggregates as guidelines for monetary policy in their communication with the public. Yet, it is quite clear that the ultimate objective for both the Bundesbank and the Swiss National Bank was a low and stable inflation rate. ${ }^{4}$ The target growth rates of the monetary aggregates were explicitly determined with this in mind. In Svensson's terminology these central banks should have been labeled (flexible) inflation targeters, even though they used unconventional operating procedures by current standards.

Similarly, countries like the Netherlands and Austria showed that inflation could be successfully targeted by focusing monetary policy on maintaining the exchange rate stable vis-àvis a low-inflation country.

Some countries do not have the institutional infrastructure to adopt the monetary policy strategies of countries like New Zealand, the United Kingdom, or Sweden.

The Swedish Riksbank and the Bank of England have been characterized as following 'international best practice' in inflation targeting. ${ }^{5}$ Both central banks are legally independent,

\footnotetext{
${ }^{3}$ The specific monetary aggregates that were used changed over time as their relationship with inflation evolved. Reference.

${ }^{4}$ On this point, see Bernanke, et.al. (1999) for the Bundesbank and Camen, Genberg and Salemi (1990) for the Swiss National Bank.

${ }^{5}$ Svensson (2001).
} 
they announce clearly and publicly numerical targets for the rate of inflation, they explain their analysis and policy actions in quarterly 'Inflation Reports', they refer to a large number of variables as being important for the transmission of monetary policy impulses, and they have adopted a decision-making system that makes each individual directly involved in setting the interest rate personally accountable for his or her policy judgments

Many countries do not possess the institutional setup necessary to adopt the British or Swedish systems of implementing inflation targeting. Their central banks may not be legally independent but rather closely connected to the economics or finance ministry, they may not have a clear enough understanding about the monetary policy transmission mechanism to elaborate sophisticated inflation reports and policy responses to shocks, the information about the economy they have available may arrive with long lags and be subject to relative large margins of error. Should these countries be advised not to adopt inflation-targeting strategies for their monetary policy? That would be unfortunate. There is much to be gained from stating explicitly that the goal of monetary policy is to maintain a degree of price stability, no matter what the institutional and economic environment is.

Instead we should limit the definition of inflation targeting to a statement of the ultimate objective of central bank policy, and recognize that the implementation of inflation targeting is country specific, and therefore need not be the same for all. Advice from international organizations should be focused on how to design a strategy that is adapted to the circumstances of each individual country and not on the practice adopted in any particular country.

The analysis also suggests that judgments about whether a country is following an adequate monetary policy strategy should focus on the ends (low inflation) and not on the means (particular operating procedure, a particular structure of communication, etc.).

\section{Inflation targeting requires support from the government as a whole.}

In pioneering countries, notably New Zeeland, the changeover to inflation targeting was accompanied by reforms in a variety of policy areas. For the purposes of our discussion, the most important were, one the one hand, making the central bank independent from the political process and giving it a mandate to preserve price stability, and on the other hand, committing the fiscal authorities to restrain budged deficits to levels that can be financed on the private capital market without putting significant pressures on interest rates. 
Success of inflation targeting depends crucially on support of governments and politicians. It cannot be achieved by the actions of the central bank alone. Wide consensus in two areas is particularly important. When it is generally understood and accepted that monetary policy cannot have any sustained impact on real variables such as the rate of economic growth, the rate of unemployment, or the real exchange rate, but that it can achieve a moderate inflation rate over the medium term, then half the battle of defining a monetary policy strategy is won. Even independent central banks do not operate in a political vacuum. Accountability to parliaments and the transparency this requires implies that monetary policy will ultimately be judged by what elected politicians, and therefore the voters, think that the central bank should accomplish. If there is a widespread belief that monetary policy can lower the unemployment rate, support the competitiveness, and hence jobs, in the export industry, or eliminate business cycle fluctuations, then it will be very difficult for central bankers to stick to a strategy where inflation control is the primary concern. The independence of the central bank may simply be withdrawn, reference to unemployment or some related variable may be formally introduced into the remit of the central bank, or it may become personally so unpleasant for the central banker to stay on the strictly anti-inflationary course, that it will be abandoned. Hence it is essential that there is widespread agreement on the goals of central bank policy.

Formal central bank independence may not even be necessary for a successful monetary policy. If the government's overall economic policy is sound, and the public understands what the central bank can and cannot do, then the central banker will quite naturally be able to carry out an inflation targeting strategy without having formal independence. ${ }^{6}$

The other half of the battle to create an effective inflation targeting strategy requires a certain degree of consistency between monetary and fiscal policies. Large borrowing requirements by the treasury crowd out lending to the private sector and put pressure on market interest rates. An independent central bank should in principle be able to withstand pressures to monetize budget deficits, but if these become large even independence may not be sufficient. Independence is given by governments and parliaments, and can therefore be reversed. Less drastically, a higher real interest rate provoked by large-scale government borrowing implies a

\footnotetext{
${ }^{6}$ This is not to say that independence is not useful. Quite the contrary, introducing independence into law is surely a good signaling device about the intentions of the (current) government/parliament, and it can help to tie the hands of future governments/parliaments, thereby making it harder for them corrupt monetary policy. The analogy to the difference between a currency board and a traditional fixed exchange rate is instructive if not perfect.
} 
higher nominal interest rates to be consistent with the inflation target. ${ }^{7}$ If this is not taken into account, monetary policy will accidentally be too expansionary, and if it is taken into account, there is the risk that the central bank will be accused of deterring growth by raising real interest rates. Unless the public is quite sophisticated in its understanding about the interplay between budget deficits, monetary policy, and real and nominal interest rates, political pressure can easily build up making it difficult for the central bank to stick to its inflation targeting strategy.

For inflation targeting to achieve political acceptability, and therefore some degree of longevity, there must be public consensus that low inflation is the appropriate goal for monetary policy. This has implication for the communication strategy of the central bank, and indeed the government as a whole. A lot has been written on this topic, much of it from the point of view of financial markets centering on how the central bank reveals and explains particular policy decisions. ${ }^{8}$ However, for the purpose of achieving wide public support, it at least as important to enlighten and convince the general public about the fundamental goals of monetary policy, and how these can be achieved in the context of the overall economic policy of the government.

\section{Translating objectives into policy.}

Inflation targeting is about the goals of monetary policy. Achieving these goals requires choosing a policy instrument or operational target, and setting this instrument in such a way that the goal is likely to be achieved. The choice of policy instrument depends on the structure and functioning of the country's financial markets, and will not be discussed further here. ${ }^{9}$ I simply note that although most central banks in industrialized countries have chosen a short-term interest rate as the policy instrument, this need not be appropriate for all countries. In developing countries in particular, domestic money markets may not be sufficiently developed and liquid for interest rates to feasible policy instruments. In such cases some measure of the liquidity in the banking system may be a more appropriate operational target. Be that as it may, in the following I will assume that a short-term interest rate is the central bank's policy instrument.

The problem that the central bank must solve is how to set the interest rate to achieve the goal of price stability while at the same time maintaining a tolerable level of output variability. I

\footnotetext{
${ }^{7}$ Expressed in terms of the celebrated Taylor rule, the intercept of the interest rate reaction function has increased.

${ }^{8}$ See, however, Blinder, Goodhart, Hildebrand, Lipton, and Wyplosz (2001) for a recent excellent and comprehensive treatment.

${ }^{9}$ See Walsh (1998), Chapter 9 for a discussion.
} 
will argue that the solution to this problem is likely to differ from country to country because it depends crucially on the monetary policy transmission mechanism and on the shocks that the country typically faces. Two unrealistic but illustrative examples will help make the point. Suppose the economy in a country obeys the strict version of the quantity theory of money with constant velocity and an exogenous rate of growth of real income. In this case the rate of inflation will be strictly proportional to the rate of growth of the quantity of money, and the central bank's problem will be solved by setting its policy instrument so as to ensure a stable growth rate of the quantity of money. Following the celebrated Fridmanian rule will be the appropriate strategy for an inflation targeting central bank in this case.

Alternatively, consider a country where the purchasing power parity hypothesis holds relative to a trading partner that has a low and stable inflation rate. In this case, setting the interest rate so as to stabilize the exchange rate will automatically achieve the objective of the domestic inflation-targeting central bank.

Although simple, these examples show that inflation targeting can imply very different operational targets for the central bank. Maintaining a steady growth rate of the money supply or a fixed exchange rate can be effective means towards inflation targeting. The transmission mechanism of monetary policy is crucial.

Taylor (1993) suggests that a rule according to which the FED increases the interest rate when the inflation rate increases above the target rate and when output increases above the natural rate will lead to desirable outcomes in the context of the United States. ${ }^{10}$ Svensson (1999) shows that such a rule can be optimal for an inflation-targeting central bank provided the structure of the economy, in particular the lags in the effects of interest rate changes on inflation, takes a particular form. In general, however, setting interest rate according to Taylor's rule is not universally the best strategy, as the illustrative examples showed, and as Svensson (2000) proved in the context of an open economy where the exchange rate plays an important role in the transmission mechanism.

Beginning with Poole (1970), the literature on optimal policy with incomplete information has shown that both the transmission mechanism and the sources of shocks affect the optimal policy reaction function. Eichengreen (2001) applies this logic to discuss how an

\footnotetext{
${ }^{10}$ The rule was $i_{t}=1.5\left(\pi_{t}-\pi^{*}\right)+0.5\left(y_{t}-y_{n}\right)$, where $\pi_{\mathrm{t}}$ represents the current inflation rate, $\pi^{*}$ the target rate, $\mathrm{y}_{\mathrm{t}}$ the current rate of output, and $\mathrm{y}_{\mathrm{n}}$ the natural rate of output.
} 
inflation-targeting emerging market country should react to an exchange rate movement, and shows, not surprisingly, that this depends crucially on whether this movement is due to a shock in financial markets or in goods markets. An analogous point is made in Cechetti, Genberg, Lipsky and Wadhwani (2000) with respect to appropriate reaction of central banks to asset prices in general.

Svensson (1997) proposes an intuitively appealing way to express the interest rate rule for an inflation-targeting central bank, which is to set the interest rate in response to the forecast of future inflation and the forecast of the deviation of real output from its equilibrium level. This is an elegant way of stating the central bank's interest rate policy, but it does not eliminate the need to understand and take into account the transmission mechanism of monetary policy. The reason is that the forecasts of future inflation and output gaps both depend on this transmission mechanism, as does the appropriate adjustment of the interest rate to any deviations of the predicted values of inflation and output from their respective targets.

What do we conclude from this about how to make inflation targeting operational? The analysis shows that even if countries have similar goals, they may react differently to new information. Differences in transmission mechanisms and differences in the susceptibility to shocks can imply different reactions to the same event. A one-size interest-rate rule does not fit all. ${ }^{11}$ This conclusion will have important implications for the evaluation of the performance of inflation-targeting central banks and therefore of their credibility.

\section{Will inflation targeting become a victim of Goodhart's Law?}

"Goodhart's Law" asserts "that any observed statistical regularity will tend to collapse once pressure is placed upon it for control purposes". ${ }^{12}$ The example Goodhart himself pointed to in this context was the fate of money supply targeting when money demand functions ceased to be reliable for predicting the effect of changes in money growth on inflation.

Will inflation targeting suffer the same fate? To answer this question we need to keep in mind that inflation targeting is a statement about the final objective of central bank policy and not

\footnotetext{
${ }^{11}$ This is perhaps how one should interpret Mishkin's third requirement of inflation targeting quoted on page 3 above.

${ }^{12}$ Goodhart (1984), p. 96.
} 
about targeting some intermediate variable. ${ }^{13}$ Nevertheless, the implementation of inflation targeting requires the use of an empirical model of the monetary policy transmission mechanism, which is precisely a set of statistical regularities Goodhart refers to. As these have been estimated based on historical observations, we cannot be guaranteed that they will remain stable in the future. Let us see where the potential sources of instability might come from.

It helps to start by reviewing the monetary transmission mechanism in macroeconomic models frequently used for monetary policy analysis. In such models inflation results from a combination of excess demand pressures, expectations of future inflation, and price increases of imported goods. ${ }^{14}$ Monetary policy, typically associated with changes in a short-term interest rate, can only influence these indirectly. Since investment and consumption demand depend on the long term real interest rate, a change in monetary policy will only have a predictable impact to the extent that there is a reliable link between the short-term nominal interest rate and the long term real rate. As we shall see, there are reasons to believe that this link may change over time.

In an open economy, exchange rate fluctuations allow for additional transmission mechanisms. A tightening of domestic monetary policy should bring about an appreciation of the domestic currency, which will in turn have both an indirect and a direct effect on inflation. The indirect effect operates via an expenditure-switching channel the strength and timing of which depends on trade patterns as well as on the substitutability between domestic and foreign goods. The direct effect comes about both because import prices are directly affected by a change in the exchange rate, and because price-setting firms might alter domestic prices in response to foreign competition.

It is not hard to imagine changes in the economic environment that will modify the transmission mechanisms implicit in this framework. For example, the influence of the real longterm interest rate on aggregate spending presumably depends on the structure of a country's financial system, which in turn evolves over time. That could potentially alter both the strength of the interest-rate effect and the lag structure of its impact. Similarly, as the international integration of goods markets intensifies over time, the importance of the exchange rate channel may change.

\footnotetext{
${ }^{13}$ Sometimes it has been suggested that an inflation forecast can be considered an intermediate target. This case will be discussed, and found not to be very different from the general problem of instability that we are concerned with here.

${ }^{14}$ See the appendix for a mathematical formulation.
} 
Many other causes of structural change can readily be imagined. A partial list would include modifications in the term-structure relationship due to financial innovation or the change in monetary policy regime itself, changes in the price adjustment rule as internet-based trade changes the cost of such adjustments, and increased incentives to adjust prices, and increased sensitivity of prices to excess demand, due to greater international competition.

All in all, there are good reasons expect changes in the transmission mechanism over time. This implies that reaction patterns of the central bank that seem appropriate now may no longer be adequate in some years. Policy mistakes can occur, in the same way that rigid adherence to strict money growth targets led to imperfect outcomes in the past. What I have called Goodhart's modified law will surely strike again. ${ }^{15}$

\section{Is inflation targeting the Holy Grail of monetary policy?}

Judging by the fate of previous monetary policy regimes, it would be surprising if inflation targeting will be the last word on monetary policy. Earlier strategies such as interest rate targeting, monetary targeting, and exchange rate targeting have all been found wanting in many countries, and have been replaced. Of course, these strategies are of a quite different nature than inflation targeting, since they involve targeting an intermediate variable, whereas inflation targeting represents an announcement of the ultimate goal of policy.

For most economists it is uncontroversial to require a central bank to have inflation stability as its main goal. For this reason it may be thought that inflation targeting will be more long lasting than previous monetary policy regimes. There are, however, at least two reasons why this may not be so.

So far, inflation targeting has been operating in an environment with relatively low unemployment. This has facilitated building a broad consensus that inflation control should be a priority. When unemployment again becomes a problem, there is a risk that an inflation-targeting strategy will be perceived to be too inflexible, i.e. too focused on inflation as opposed to output stabilization. Pressures on the central bank will then mount to be more accommodative. Independence will not protect the central bank from such pressures as already explained in

\footnotetext{
${ }^{15}$ It is worth pointing out that a strategy based on inflation forecast targeting will not be immune to problems of instability of the transmission mechanism, both because inflation forecasts are by necessity conditional on some model of the economy, and because correct instrument settings will in any case be a function of the nature of the transmission mechanism.
} 
section 3. To the extent that the government determines the objectives of monetary policy, it would be possible to require the central bank to pay more attention to unemployment without altering its legal independence. One can even imagine a situation where inflation stability will be subordinated to an unemployment goal, the antithesis of inflation targeting.

To reduce the probability of this happening, it is important that the public at large and politicians are well informed about what monetary policy can and cannot accomplish. The importance of educating the public about this in advance cannot be underestimated.

Another threat to inflation targeting may emerge if implementation turns out to be based on a too static view of the transmission mechanism, e.g. if the central banks will be drawn into adopting some rigid policy rule. There is a tendency in the debate about monetary policy to associate inflation targeting with setting interest rates according to a Taylor rule. This may come from the perception that the Fed is following such a rule combined with the success of monetary policy in the US during the 1990s. Be that as it may, when the link between policy instruments and inflation changes, as it certainly will, reaction patterns of central banks need to adapt. If that is not done, outcomes for both inflation and output stability will deteriorate, and the inflation targeting strategy will be called into question. 


\section{Appendix: A stylised model of the monetary transmission mechanism.}

It helps to start by reviewing the monetary transmission mechanism in a stylized model. ${ }^{16}$ Such a model typically would consist of at least the following four equations. ${ }^{17}$

$$
\begin{aligned}
& y_{t}=\alpha_{0}+\alpha_{1}\left(i_{\mathrm{t}}^{\mathrm{L}}-\pi_{\mathrm{t}+\mathrm{n}}^{\mathrm{e}}\right)+\alpha_{2} e_{t}+\alpha_{3} y_{t+1}^{e}+\varepsilon_{t}^{1} \\
& i_{t}^{L}=\mathrm{E}_{\mathrm{t}}\left[\mathrm{f}\left(i_{\mathrm{t}}^{\mathrm{S}}, i_{\mathrm{t}+1}^{\mathrm{S}}, \ldots, i_{\mathrm{t}+\mathrm{n}}^{\mathrm{S}}, \ldots . .\right)+\varepsilon_{t}^{2}\right. \\
& \pi_{\mathrm{t}}=\beta_{0}+\beta_{1} \pi_{\mathrm{t}+1}^{\mathrm{e}}+\beta_{2} \Delta E_{t}+\beta_{3}\left(y_{t}-y_{t}^{n}\right)+\varepsilon_{t}^{3} \\
& i_{\mathrm{t}}^{\mathrm{S}}-i_{\mathrm{t}}^{*}=\Delta E_{t+1}^{e}+\varepsilon_{t}^{4}
\end{aligned}
$$

where

$y=$ real output (income)

$i^{L}\left(i^{S}\right)=$ the long term (short term) nominal rate of interest

$\pi=$ the rate of inflation

$E(e)=$ the nominal (real) exchange rate

$\varepsilon=$ random shocks to the economy

Equation (1) is a relatively standard IS relationship where aggregate demand depends on the long-term ex ante real interest rate, the real exchange rate, and expected real income.

Equation (2) reflects a term structure of interest rate relationship in which the nominal long rate is a function of the current short rate, the future expected short rate, and other not specified variables. Equation (3) represents a price adjustment rule or a Phillips curve that includes an effect due to the pass-through of nominal exchange rate changes to the domestic inflation rate in addition to the usual effects due to expected inflation and a measure of excess demand. According to the interest parity relationship [equation (4)] the differential between the domestic and the foreign interest rate is equal to the expected change in the exchange rate plus a risk premium that is simply written as a random error term. Finally, the Central Bank is assumed to control the nominal short rate.

In this type of framework, a change in central bank policy will influence inflation only indirectly, and with a lag that depends on which mechanism we focus on. As an illustration, note that for a change in the short rate to influence domestic demand for goods, it must first influence the nominal long-term rate through equation (2). It will then influence spending to the extent that the change in the long-term nominal rate also translates into a change in the corresponding real rate. Finally, a change in spending will have an impact on inflation that depends on how pricesetting firms react to increased orders and sales.

In an open economy, exchange rate fluctuations allow for additional transmission mechanisms. A tightening of domestic monetary policy should bring about an appreciation of the domestic currency, which will in turn have both an indirect and a direct effect on inflation. The indirect effect operates via an expenditure-switching channel on aggregate demand (the term $\alpha_{2} \mathrm{e}_{\mathrm{t}}$ ) the strength and timing of which depends on trade patterns as well as on the substitutability between domestic and foreign goods. The direct effect comes about both because import prices

\footnotetext{
${ }^{16}$ See for example Svensson(2000) and Walsh(1998), Ch. 10.

${ }^{17}$ Although the discussion that follows assumes that there are lags in the relationships described by equations (1) (4), these have, for simplicity, not been made explicit in the formulas.
} 
are directly affected by a change in the exchange rate, and because price-setting firms might alter domestic prices in response to foreign competition (the term $\beta_{2} \Delta \mathrm{E}_{\mathrm{t}}$ in equation (4)).

As discussed in the text, there are no reasons to believe that these relationships will remain constant over time as the structure of the economy and the external environment undergoes changes. As the relationships defining the link between the policy instrument and the ultimate policy objective is altered, the reaction of the central bank must necessarily adapt if the economic performance is not to deteriorate. 


\section{References}

Bernanke, Ben, Thomas Laubach, Frederic Mishkin, and Adam Posen (1999). Inflation Targeting: Lessons from the International Experience. Princeton, NJ: Princeton University Press.

Blinder, Alan, Charles Goodhart, Philip Hildebrand, David Lipton, and Charles Wyplosz (2001). "How do Central Banks Talk?”. Geneva and London: ICMB and CEPR, 2001.

Camen, Ulrich, Hans Genberg, and Michael Salemi (1990) "Optimal Monetary Policy and the Revealed Preference Function of the Swiss National Bank". In P. Artus and Y. Barroux (eds.), Monetary Policy, A Theoretical and Econometric Approach. Dordrecht: Kluwer Academic Publishers, 1990, pp. 3-14.

Cechetti, Stephen, Hans Genberg, John Lipsky and Sushil Wadhwani (2000). Asset Prices and Central Bank Policy. Geneva and London: ICMB and CEPR, 2000.

Eichengreen, Barry (2001). “Can Emerging Markets Float? Should they Inflation Target?”, mimeo. April. http://emlab.berkeley.edu/users/eichengr/nicaragua3.pdf

Goodhart, Charles (1984). Monetary Theory and Practice the U.K. Experience. London: Macmillan.

Mishkin, Frederic (2000). "Inflation Targeting in Emerging-Market Countries", American Economic Review, Papers and Proceedings, Vol. 90, No. 2, May, pp. 105-109.

Poole, William (1970) "Optimal Choice of Monetary Policy Instruments in a Simple Stochastic Macro Model”. Quarterly Journal of Economics, vol. 84, pp. 197-216.

Svensson, Lars (1997). "Inflation Forecast Targeting: Implementing and Monitoring Inflation Targets," European Economic Review 41, pp. 1111-1146.

Svensson, Lars (1999). "Inflation Targeting as a Monetary Policy Rule," Journal of Monetary Economics 43. pp 607-654.

Svensson, Lars (2000). “Open Economy Inflation Targeting”. Journal of International Economics 50, pp. 155-83.

Svensson, Lars (2001). "Independent Review of the Operation of Monetary Policy in New Zealand”, http://www.iies.su.se/leosven/NZ/RevNZMP.htm

Taylor, John (1993). "Discretion versus Rules in Practice". Carnegie-Rochester Conference Series on Public Policy, vol. 39, pp. 195-214.

Walsh, Carl E. (1998). Monetary Theory and Policy. Cambridge, Massachusetts: The MIT Press. 